\title{
ATRACTIVIDAD TERRITORIAL Y CEMENTERIOS INDUSTRIALES. FORTALEZAS Y DEBILIDADES DE LA REESTRUCTURACIÓN INDUSTRIAL EN LA REGIÓN METROPOLITANA DE BUENOS AIRES
}

\author{
Horacio BOZZANO \\ Universidad Nacional de La Plata. Argentina.
}

\section{INTODUCCIÓN.}

El actual contexto de la reestructuración industrial reposiciona a la metrópolis de Buenos Aires como primer territorio en Argentina atractor de inversiones industriales, desplazando la tendencia inducida por medio de políticas de promoción regionales y sectoriales que durante medio siglo -con intervalos- había intentado reequilibrar trayectorias territoriales diferentes entre el interior del país, menos atractivo, por un lado, y las grandes ciudades con la mayor trayectoria industrial, por otro lado; nos referimos particularmente a Buenos Aires, pero también a Córdoba, Rosario y Mendoza.

Entre las opciones dominantes de reestructuración industrial en la Argentina ${ }^{1}$, prevalecen en la Región Metropolitana de Buenos Aires (RMBA) aquellas de compras, asociaciones y fusiones de empresas extranjeras, que tienden a agrandar la brecha entre ganadores y perdedores, reduciendo la competencia y los márgenes de maniobra y negociación adquiridos por el empresariado Pyme de la región durante una buena parte de la historia industrial previa.

En este contexto de aparente ventaja de Buenos Aires, exponemos que al interior de la RMBA no todo es atractividad territorial para la industria, sino que al menos hay otras tres lógicas de la reestructuración que coexisten de manera compleja y se yuxtaponen en los territorios. El despliegue heterogéneo de estas cuatro lógicas nos conduce a proponer cuatro territorios de la reestructuración industrial dominantes en la RMBA. Se trata de medios con "atractividad territorial genuina", aquellos con "pseudo-atractividad", los "territorios mixtos" mas autónomos en relación al proceso de reestructuración y el "cementerio industrial" de la primera corona metropolitana.

Como veremos a continuación, al interior de los territorios subyacen trayectorias industriales, matices de una cultura industrial, opciones mas o menos genuinas, fusiones y adquisiciones de empresas, reconversiones en procesos y productos, cambios organizacionales, despliegues políticas, estrategias

\footnotetext{
${ }^{1}$ A partir de MonZA (1993), KosACOFF (1995) y de la investigación realizada entre 1992 y 1998 identificamos cuatro componentes de la reestructuración industrial; en resumen se trata de fusiones y adquisiciones, de cambios en el peso relativo de ramas, sectores y nichos de reconversion tecnológica en procesos y productos, y de mutaciones organizacionales.
}

Polígonos, $\mathrm{n}^{\mathrm{o}}$ 10, 2000, pp. 137-153. 
económicas, modalidades de inserción en el Mercosur, conflictos ambientales ... ¿Qué va surgiendo de estas complejas relaciones frecuentemente ocultas? Ganadores y perdedores, amenazas y oportunidades, fortalezas y debilidades....

No son todos los ganadores quienes crean fortalezas genuinas en el territorio, encontramos también "cuasi-enclaves" de una dudosa atractividad territorial. Los tejidos mixtos se confunden a veces entre una dificil convivencia vivienda-tallerdepósito-industria por una parte, y la amenaza de desaparecer como tal, por otra. Fecuentemente, éstos se refuncionalizan hacia el tejido urbano consolidado o bien no devienen una cosa ni la otra. En el peor de los casos podemos llegar a reconocerlos como cementerios industriales.

El propósito de la investigación ${ }^{2}$ es identificar las fortalezas y las debilidades de los territorios industriales metropolitanos a partir de la hipótesis de las cuatro lógicas de ocupación mencionadas. La intención final es ofrecer opciones de políticas territoriales concretas para las gestiones locales en el contexto de una estrategia global a nivel nacional, no solamente orientada a los ganadores sino también a los perdedores ${ }^{3}$.

En este trabajo comenzaremos a analizar los rasgos significativos de la reestructuración industrial actual, para identificar luego quienes ganan y quienes pierden. Esto nos permite reconocer fortalezas y debilidades de la cultura industrial. Y es a partir de allí que comenzaremos a exponer nuestra "mirada" territorial: la atractividad, los cementerios y otros medios industriales, para continuar con el territorio y la industria en la metrópolis a tres escalas: macro, meso y micro. Esquemáticamente, el abordaje "reestructuración, ganadoresperdedores, fortalezas-debilidades, atractividad-cementerios, territorio-industria" nos permite introducir finalmente niveles de propuestas en cuanto a una política territorial para la industria en una gran metrópolis de un país no central.

\section{RASGOS DE LA REESTRUCTURACION INDUSTRIAL.}

Sobre las manifestaciones heterogéneas del actual proceso de reestructuración industrial surgen disímiles trayectorias tecno-productivas que nos permiten comprender la diferente inserción de cada país según se trate de los países llamados "innovadores", "imitadores creativos" o "de industrialización tardía". Aún considerando que la trayectoria industrial y el sendero tecnológico de vanguardia en América Latina haya situado a Argentina -en ciertos nichospróximo a la frontera de innovación, el despliegue actual de la reestructuración en Buenos Aires, su región industrial por excelencia, no parece seguir el mismo camino. El nivel de industrialización alcanzado por la RMBA en el momento de la reestructuración, no obstante no estar situado en la vanguardia tecnológica, era

\footnotetext{
${ }^{2}$ Se trata de una tesis de doctorado recientemente sostenida sobre "Los Territorios de la Reestructuración Industrial en la Región Metropolitana de Buenos Aires” entre 1992 y 1999, bajo la dirección de Jean RevelMouroz, en la Universidad de Paris III-Sorbonne Nouvelle.

${ }^{3}$ Se trata de una investigación realizada para el CEB, Centro de Estudios Bonaerense, en un Proyecto de las Naciones Unidas PNUD Argentina 94/013 de la Secretaría de Industria de la Nación: "Parques, Sectores Industriales Planificados y Zonas Industriales de la Provincia de Buenos Aires. Bases de datos y evaluación de la localización existente". La primera etapa ha sido finalizada en Febrero de 1999. Se preve profundizar esta investigación con el propósito de hacerla cada vez mas aplicada.
} 
muy importante ${ }^{4}$.

Los tiempos de la desindustrialización y los de la reestructuración industrial han sido breves, crudos, sin transiciones y sin anestesias porque ellos se han ido gestando por un lado, por la debilidad -inducida o no inducida- del poder reivindicativo que durante una buena parte de la trayectoria industrial argentina, han tenido trabajadores y sindicatos; y por otra parte, por las variaciones en los senderos industriales del empresariado argentino hacia otras opciones coyunturales más ventajosas. Aún reconoceindo ensayos exitosos, no observamos todavía una política industrial sólida, de apoyo a todos los sectores reestructurados, los ganadores y los perdedores.

Es probable que la reestructuración económica global esté dando lugar en Buenos Aires a una reformulación de la "sociedad de empate"5 que se produjera entre el modelo agroexportador y el de industrialización sustitutiva. Más que una estrategia industrial, genuina y durable la naturaleza de la reestructuración se aproxima cada vez más a la fase de un tipo territorial denominado "burbuja" (NOCHTEFF, 1994).

Cuando la reestructuración ingresa en la Argentina, tiende a dominar la lógica económica de la competitividad, las políticas económicas de la reestructuración surgen a posteriori, frecuentemente como paliativos, y las políticas de trabajo son las últimas en incorporarse una vez que el tema del desempleo se instala como no lo había hecho nunca en la sociedad. Entre las opciones dominantes de la reestructuración industrial prevalecen en la RMBA aquellas de compras, asociaciones y fusiones de empresas extranjeras, que tienden a agrandar la brecha entre ganadores y perdedores, reduciendo la competencia y el margen de maniobra adquirido por el empresariado Pyme de la región durante una buena parte de la historia industrial previa.

La reconversión industrial en procesos y en cambios organizacionales domina entre las grandes empresas extranjeras, y en menor medida entre las nacionales. La tendencia incipiente a la reconversión organizacional en algunos sectores comienza a borrarse, alejando cada vez más la posibilidad de generar las bases para la difusión de un proceso generalizado de innovación por reconversión en procesos y productos. Se trata de una de las opciones más restrictivas al desarrollo de una cultura industrial local. En lo concerniente a las Pymes, la lógica de la reestructuración industrial no tiende a expulsar la mano de obra por cambio tecnológico incorporado, ni a captar desempleados de grandes empresas; sino sobre todo con el cierre de empresas Pymes- a expulsar trabajadores del sector formal. Las microempresas de servicios, comerciales e industriales son en general el principal refugio, lo que contribuye a incrementar cada vez más el sector informal urbano.

En este contexto, la reestructuración industrial contribuye a generar un "efecto

\footnotetext{
${ }^{4}$ A partir de la investigación realizada identificamos que entre los siete "motivos de venta industrial" publicados, $90.7 \%$ de las fábricas tenía maquinaria industrial en sus establecimientos. Se puede deducir que la propia dinámica de reconversión es más importante que otros fenómenos como la relocalización, el cambio de rama o de nicho, o la disolución de sociedades.

${ }^{5}$ Nos referimos aquí a que los modelos agroexportador y de industrialización sustitutiva no se habrían sacado ventaja entre ellos. A propósito de esta atractiva hipótesis, creemos que hay mucho por investigar en lo relativo al arraigo y al carácter genuino de una cultura del agro, por un lado y de una cultura industrial, por el otro.
} 
de cascada", donde el conflicto generado por la concentración económica en las grandes empresas influye sobre las Pymes, cuyo cierre refuerza el rol de refugio de las microempresas. La sociedad adopta una estrategia económica "dual" y la brecha se agranda entre las lógicas siempre más competitivas y aquellas de "superviviencia" cada vez más frecuentes.

En esta investigación la reestructuración industrial más profunda identificada es la del complejo automotriz en la Argentina. En cinco o seis años se multiplica por cuatro la producción de automóviles, tres de las seis grandes firmas mundiales se instalan, manteniendo el mismo nivel de empleo y dos tercios de los establecimientos se fusionan o bien desaparecen ${ }^{6}$. La reciente convulsión económica en Brasil parece introducir restricciones al desarrollo del complejo automotriz argentino.

Otro rasgo importante de la reestructuración es el de las estrategias de implantación de empresas extranjeras ${ }^{7}$. En lo concerniente a inversiones directas francesas, éstas son heterogéneas por rama pero con un rasgo dominante común: los nichos de mayor valor agregado. Entre las 72 empresas industriales francesas instaladas en Argentina en 1996, no se observa el control de un sector, siendo importantes aquellas de alto valor agregado -de apoyo a las telecomunicaciones, la electrónica y los aparatos de precisión-, las intensivas en recursos naturales petróleo, alimentos y bebidas- $\mathrm{y}$ aquellas del complejo automotriz: terminales y autopartistas.

\section{3. ¿QUIÉNES GANAN Y QUIÉNES PIERDEN?.}

La reestructuración industrial no concierne sólo a los grandes empresarios, sino también a los Pyme, los micro y a todos los trabajadores industriales. En niveles institucionales se incluyen los instrumentos de política y aquellas acciones que -frecuentemente por omisión- marginan otras cuestiones. Es en este contexto que surgen ganadores y perdedores.

Los ganadores de la reestructuración industrial de la RMBA son los "comandos"de las empresas transnacionales y las grandes plantas hipercompetitivas del Mercosur, pero también las Pymes que -eslabonadas a éstasluchan por mantenerse en la carrera de la competitividad. Los ganadores de la reestructuración son las transnacionales que debutan en la Argentina, pero también son las empresas nacionales que han ido madurando en trayectorias industriales de dos, tres o cuatro generaciones.

Los perdedores de la reestructuración industrial de la RMBA son las Pymes

\footnotetext{
${ }^{6}$ De ocho usinas de montaje y 1500 empresas distribuidas en proporciones casi iguales entre subcontratistas de primero o de segundo nivel de terminales y autopartistas, se pasa en pocos años a un complejo compuesto por 11 terminales automotrices, 7 u 8 grupos empresariales proveedores de conjuntos o subconjuntos, 40 a 60 Pyme medianas en aceptables condiciones de competitividad, 280 Pymes pequeñas integrantes de una red de proveedores que había incorporado o estaba incorporando el just-in-time en sus procesos productivos, y por último, otros 200 proveedores entre los que dominaban aquellos ligados al mercado de piezas de reposición.

${ }^{7}$ Las empresas francesas adoptan preferentemente una estrategia gradual en Argentina, que comienza en general por un representante de una sociedad local que establece relaciones con una empresa francesa. La consolidación de la actividad deriva frecuentemente en la creación de una oficina de representación de la sociedad-madre francesa, no disponiendo de presupuesto propio. Finalmente se crea la filial, toda sociedad creada o adquirida por una empresa francesa que posea como mínimo un $10 \%$ del capital.
} 
que no pueden alcanzar los stándares de calidad internacional cada vez más competitivos exigidos por la reconversión; éstas empresas no pueden insertarse siquiera parcialmente en mercados externos. Los perdedores son también las microempresas que, no siendo competitivas con las Pymes ni con las grandes, no pueden mantenerse dentro de sus lógicas de sobrevivencia.

Las ramas y sectores ganadores son la automotriz, la farmacéutica, las bebidas alcohólicas, algunos sectores intensivos en escala y en capital, como por ejemplo la siderurgia, la petroquímica, la destilación de petróleo y el aluminio, y los sectores de tradición agro-exportadora, en particular los complejos aceitero y harinero y la industria frigorífica. En el complejo automotriz y en el sector farmacéutico, se distinguen la reconversión en procesos y la calificación, mientras que en general el resto registra importantes inversiones en equipos.

Las ramas y sectores perdedores son en general la metalúrgica y otros bienes de capital, entre los cuales sobresalen algunos sectores como los de máquinasherramienta o la micro-electrónica que, habiendo alcanzado niveles de desarrollo tecnológico local considerables, comienzan a recibir los efectos del nuevo contexto de apertura de la reestructuración. Algunos otros sectores, más intensivos en trabajo, como el textil, prendas de vestir, calzado y algunos nichos de las industrias alimenticias y del mueble, sufren la competencia, particularmente del Sudeste asíático.

Aún considerando que la mayoría de los territorios de la reestructuración industrial combinan ganadores y perdedores, los territorios ganadores en la RMBA dominan en las periferias conectadas con Buenos Aires y el Mercosur; mientras que los territorios perdedores son los galpones vacíos del cementerio industrial de la primera corona metropolitana desarrollados durante las fases de industrialización sustitutiva.

La ola reestructuradora alcanza de manera directa o indirecta todo el universo industrial. Unos ganan, otros pierden, algunos se confunden sin alcanzar estos extremos: pero en le fondo encontramos una cultura industrial. El Estado, los empresarios y los trabajadores, todos articulados construyen, reconstruyen o bien destruyen la cultura industrial.

\section{FORTALEZAS Y DEBILIDADES DE LA CULTURA INDUSTRIAL.}

El contexto social, político y económico anterior a 1990 contribuye a generar el escenario para que la reestructuración industrial se incorpore con fuerza y sin transiciones. Se trata de un contexto de debilidad generalizada de una cultura industrial $^{8}$, manifiesta en sectores empresarios, en el movimiento obrero, en sindicatos y en las instituciones encargadas de formular las políticas industriales propiamente dichas. En contrapartida, la consolidación de una "élite económica" se manifiesta en una orientación que terminaría privilegiando opciones de inversión en otros sectores, principalmente comerciales, de servicios e inmobiliarios.

\footnotetext{
${ }^{8}$ La cultura industrial es concebida a partir de la presencia de una trayectoria de complejos despliegues y articulaciones de empresarios, trabajadores y actores públicos, no siempre con éxito, que permiten reconocer niveles de desarrollo industrial genuinos con una base de sustentación que favorece su consolidación.
} 
Hoy la consolidación de la cultura industrial tiene "amenazas y oportunidades" (Jordi Borja) ligadas al despliegue de los cuatro componentes de la actual reestructuración industrial. A medida que las amenazas y oportunidades se concretan, se materializan, se van gestando "fortalezas"y "debilidades" no solamente en los rasgos característicos dominantes del conjunto de los actores, sino también en los territorios emergentes.

Las amenazas tienden a concentrarse en el peso que desde 1994 adquiere en la Argentina una dinámica de fusiones y adquisiciones de empresas donde la transnacionalización y las grandes firmas extranjeras prevalecen sobre las líderes del mercado nacional ${ }^{9}$. En la medida que el sendero industrial de los próximos años consolide estas opciones de reestructuración con una inserción creciente en la economía global, el margen de maniobra de las grandes y las Pymes con trayectoria industrial local tenderá a reducirse en Buenos Aires, provocando debilidades en el núcleo de la cultura industrial.

Las nuevas oportunidades se presentan a través de la introducción de capacidades tecnológicas, las cuales con muchas variantes, incluyen gradualmente Pymes y grandes empresas locales con trayectoria industrial en términos de reconversión tecnológica en procesos y productos y en mejoras en la gestión, organización y calificación dentro de la empresa; esta situación contribuye a mejorar la competitividad, reposicionándose en el mercado local, estableciendo redes con las grandes y/o ampliando su perfil exportador. Hoy las fortalezas del núcleo de la cultura industrial se observan en un conjunto importante de empresas que han mejorado su conducta tecnológica en ramas y nichos muy heterogéneos.

Las oportunidades se presentan también en las pequeñas e innumerables mejoras organizacionales -estimuladas indirectamente por el propio proceso de reestructuración industrial- que gradualmente incorpora, no sin esfuerzo, a una buena parte de los microempresarios y los pequeños industriales. Su lógica de funcionamiento está más alejada de la reestructuración industrial que la del resto de las empresas. Aquí las fortalezas se orientan particularmente hacia modelos de consumo urbano generalmente arraigados en la sociedad; ellos no constituyen el núcleo, aunque sí es posible reconocer el germen de una cultura industrial con fuerte arraigo.

A un nivel de análisis macro, hay otra amenaza histórica. Una inercia de dos o tres generaciones, bastante difundida, manifiesta en un sendero donde el cambio tecnológico no ha sido líder del proceso, sino más bien secundario; una trayectoria donde el peso de sindicalismo en el movimiento obrero ha tendido a fragmentar las relaciones de poder de este movimiento; una cultura donde el empresario no ha podido ni ha sabido sobrellevar totalmente aquellas restricciones; una cultura que ha reposado durante largos períodos en la protección nacional de la sustitución de importaciones. La permanencia de estas dificultades estructurales en lo relativo a la formación de una cultura industrial no haría sino consolidar las debilidades.

\footnotetext{
${ }^{9}$ La reestructuración industrial en la Argentina, según la dinámica de adquisiciones, es la más importante de América Latina. En 1994 y 1995, en Argentina la venta de empresas duplica el valor de las vendidas en Chile, supera en un $30 \%$ a las de Brasíl y en un $25 \%$ a las de México. Esta faceta de la reestructuración puede transformarse en negativa en pocos años si consideramos que se interrumpen importantes senderos industriales locales.
} 
En el actual contexto de reestructuración industrial surge una oportunidad histórica para el Estado: la reestructuración efectiva y no retórica de su política industrial. La superación de políticas de protección propias de fases sustitutivas y el reposicionamiento de numerosos programas y regímenes sectoriales en vigencia y en proyecto deberían compartir en la práctica un supuesto de base común: el rol del Estado como articulador de competitividad, desencadenando innumerables oportunidades que ofrece la reestructuración para cada rama y para muchos nichos. Las fortalezas y las debilidades surgirán en la medida que las políticas se aproximen o se alejen respectivamente de un sendero industrial mas genuino.

En este complejo contexto de consolidación y deterioros simultáneos de una cultura industrial genuina, no todos los ganadores de la reestructuración industrial tenden a general fortalezas genuinas. Los nuevos gigantes del Mercosur y otras grandes firmas nacionales o internacionales con trayectoria en Argentina generan "fortalezas intra-firma" priorizando sus estrategias mundiales al interior de cada empresa por sobre la consolidación de redes horizontales o verticales con otras empresas en las metrópolis de países periféricos.

Si las oportunidades emergentes de los intrumentos de política industrial se orientan crecientemente hacia la consolidación de las fortalezas "intra-firmas" de los grandes del Mercosur, más que a consolidar eslabonamientos con otras grandes y Pymes locales, es probable que veamos abrirse un cuadro de debilidad más generalizada. Esta situación daría las bases de la "pseudo-atractividad territorial".

Hoy la reestructuración industrial muestra claramente todas las opciones: los ganadores y los perdedores, las amenazas y las oportunidades, las opciones más genuinas y aquellas de grandes firmas que formulan y ejecutan sus estrategias en países con débiles políticas industriales. Los supuestos básicos subyacentes de la atractividad territorial y la pseudo-atractividad están manifiestos, pero también las otras lógicas de ocupación: los "cementerios industriales" y los "territorios mixtos" más autónomos a la ola reestructuradora ${ }^{10}$.

\section{ATRACTIVIDAD TERRITORIAL, CEMENTERIOS INDUSTRIA- LES.}

Mientras que la atractividad está ligada a una industrialización más arraigada y genuina -hoy competitiva- posicionando de manera ventajosa a Buenos Aires, las otras lógicas se alejan de ella. Una tiende a formar los territorios hipercompetitivos de las grandes firmas internacionales a nivel mundial, pero bastante alejados de los entornos industriales locales. La otra lógica se mantiene bastante arraigada por su trayectoria industrial ligada al consumo urbano -el tejido mixto-

\footnotetext{
${ }^{10}$ Estos cuatro territorios con nombre y apellido no surgen automáticamente del análisis del proceso de reestructuración, ni de la identificación de ganadores y perdedores, tampoco de los rasgos principales de la cultura industrial. En todo caso se trataría de subrayar las espacialidades a partir de todas estas situaciones que no son necesariamente "espacializables". En este contexto planteamos que el concepto territorio es aposterio$r i$, y que se construye a partir de la articulación sucesiva de cinco instancias de aproximación: los órdenes del ser -fisico, biológico, histórico y psicológico-simbólico-, los niveles de análisis -macro, meso y micro, las dimensiones de análisis -socio-cultural, política, económica, fisica natural y fisica construida-, las temporalidades y las espacialidades. La territorialidad surge como una combinación particular de espacialidades que responden a procesos, lógicas y fenómenos de todas las dimensiones y de todos los niveles analíticos mencionados.
} 
mientras que la restante es aquella que, propia al pasaje de modelos más fordistas a modelos más flexibles, contribuye a generar baldíos industriales en una buena parte de los territorios: se trata de los "cementerios industriales".

Los ámbitos con mayor atractividad territorial ${ }^{11}$ son aquellos que ofrecen más oportunidades para la instalación, el desarrollo, el eslabonamiento y la consolidación de industrias y de establecimientos asociados. Su territorialidad se define por su medio industrial local, medido en la presencia de "capitales formales" y "rentas organizacionales" (JAVET, 1993) pero también por la relación con las lógicas de ocupación vecinas, la conexión con cuencas de empleo y subempleo, la accesibilidad metropolitana, la accesibilidad a mercados macroregionales, las ventajas fiscales y el cuadro legislativo.

Es necesario agregar que, en las condiciones actuales, la reestructuración industrial en la RMBA, no ofrece atractividad territorial -ni siquiera las bases necesarias- para generar actualmente un complejo industrial científicotecnológico y superar los importantes casos desarrollados en el primer medio siglo; no hay tampoco condiciones suficientes para crear polos tecnológicos ni tecnópolis con atractividad territorial genuina.

Los medios con "pseudo-atractividad territorial" son los ganadores de hoy que no tienden a desarrollar conexiones con los medios locales, ni tampoco establecen relaciones significativas en su entorno, a excepción de las indispensables para lograr una inserción comercial en los mercados de los países periféricos donde se instalan. Su territorialidad está cercana a una nueva versión de los antiguos "enclaves industriales", donde las grandes firmas tienden a establecer sus territorios mundiales a partir de redes planetarias ligadas en mayor medida a encadenamientos intra-firma entre sitios distantes que a redes locales de subcontratación.

Los "territorios mixtos" son -entre los territorios industriales- los más autónomos al proceso de reestructuración industrial, considerando que la industria propia de estos lugares sobrevive a dicho proceso y "cohabita" con los barrios donde se asienta. Ello permitiría reconocer una fuerte tendencia a la estabilidad tanto en su trayectoria local como en su perfil industrial. Su territorialidad se define por la coexistencia y la yuxtaposición de dos espacialidades: una ligada a su consolidación local y la otra al actual redespliegue de microempresas y Pymes sobre todo pequeñas que, incorporando algunos cambios en su organización y gestión empresarial, continúan con sus lógicas de producción ligadas al consumo urbano.

El "cementerio industrial" de la PCM deviene el mayor perdedor de la reestructuración industrial, donde se produce el mayor contraste entre el sendero industrial previo y la imposibilidad de reconvertir la industria. Coincide en general con los medios de mayor pasivo ambiental, situación que tiende a complejizar su destino urbano. Su territorialidad se construye, se deconstruye y se reconstruye

\footnotetext{
${ }^{11}$ La atractividad territorial y la "pseudo-atractividad" de la RMBA no es solamente industrial; ella se observa actualmente en pequeñas y numerosas porciones de una metrópolis conformada por algunos medios residenciales y "cuasi-enclaves" comerciales y de servicios, distribuidos en una región dominada por lógicas de ocupación donde tienden a deteriorarse las condiciones de vida y el acceso al empleo. La espacialidad de la inversión publica, privada y concesionada en infraestructuras sociales y económicas contribuye a profundizar la dualidad del espacio urbano.
} 
en no menos de dos generaciones de implantación industrial de espacialidades industriales desde su origen.

Estos cuatro tipos territoriales no superan el $1 \%$ de la superficie total de la RMBA $^{12}$, ni tampoco se trata de territorios donde hemos verificado un patrón territorial determinado; en la mayoría de los casos estos se presentan mezclados con otras lógicas de ocupación. Pero, en todo caso, si el objetivo es proponer instrumentos de política territorial para su ordenamiento es necesario trabajarlos tal cual se presentan. Por lo tanto, es necesario incorporar los medios donde se insertan: el escenario se llama Buenos Aires.

\section{BUENOS AIRES: TERRITORIO E INDUSTRIA.}

Buenos Aires es uno de los tres o cuatro mayores mercados urbanos del mundo entre los países periféricos, caracterizados por una importante concentración económica en ramas industriales, comerciales y de servicios, un descenso generalizado en los niveles de ingreso de la "clase media argentina", notables desigualdades sociales y económicas, y tendencias crecientes a la fragmentación territorial.

La RMBA concentra, en $4.556 \mathrm{~km}^{2}$, una población de 13,2 millones de habitantes, un universo industrial de 28.400 microempresas, 14.000 Pymes, 1.500 establecimientos grandes y medianos, con un total de 550.000 empleos industriales y un universo metropolitano de 158.000 manzanas, 4,5 millones de parcelas urbanas y 44.000 fracciones intersticiales y periurbanas, distribuídas en 41 distritos municipales.

Para alcanzar algunos niveles propositivos de política territorial concretos, trabajamos desde el comienzo con una concepción que se sustenta en la gestión del territorio. Ella intenta articular tres niveles analíticos: macro, meso y micro ${ }^{13}$, a partir del trabajo, la investigación y la maduración de los mayores niveles de consenso posibles, entre los principales referentes directos e indirectos del proceso estudiado.

La escala macro: Definimos al proceso de organización territorial de la RMBA por cinco instancias dominantes de un ciclo que desde el origen de la ciudad mantiene en términos generales su estructura y la reproducción de dicha estructura $^{14}$, es decir, ese juego continuo entre la permanencia y la redefinición

\footnotetext{
${ }^{12}$ En nuestra investigación habíamos establecido siete puntos de partida, siendo uno de ellos el siguiente: "el carácter no dominante de la industria en el territorio metropolitano, tanto en lo concerniente a otras lógicas de ocupación urbanas y periurbanas, como en relación a su significación en términos espaciales, sociales, económicos y ambientales”. (BozZANO, 1999)

${ }^{13}$ En la escala macro nos referimos a la organización territorial (CORAGGIO, 1979), en la escala meso tratamos las lógicas de ocupación, mientras que a nivel micro trabajamos con los patrones territoriales.

${ }^{14}$ En el capítulo original de la tesis doctoral al referirnos a las transformaciones territoriales de la RMBAdesde 1580 hasta 1980, subyacen las cinco instancias del proceso de organización territorial. La primera se perfila claramente a partir de la decisión de sus fundadores de diferenciar la ciudad, de las "tierras de pan llevar" y las "suertes de estancia" para el caso de Buenos Aires, y dos a tres siglos mas tarde, por la materialización de subdivisiones urbanas y rurales generalmente con estaciones ferroviarias, aquellas que devendrían mas tarde en los principales subcentros metropolitanos. Esta impronta catastral recibe la impronta socio-cultural y las inversiones publicas que lentamente consolidan y fortifican los territorios; la instancia de estancamiento domina en los primeros siglos de Buenos Aires, mientras que la retracción se reduce a cortos períodos de las mayores crisis; vale decir que es posible reconocer en Buenos Aires las cinco instancias de este proceso. En una redu-
} 
permanente del territorio. Referida a ámbitos urbanos y periurbanos, se trata en síntesis de: 1) la creación y la expansión, 2) la consolidación, 3) la fortificación, 4) el estancamiento y 5) la retracción ${ }^{15}$. Hay otras situaciones que, de diversa manera integran estas instancias; hacemos referencia a la refuncionalización, a la recuperación y a otras modificaciones de diversos ámbitos metropolitanos. En estos casos se trataría de lógicas y de formas particulares de ocupación.

Bien o mal hecha, la industrialización ha construído una cultura industrial en Buenos Aires durante más de un siglo de su historia. Sólo una década ha bastado para destruir una buena parte de ella... Y menos tiempo aún para que la industria se reestructure, con ganadores y perdedores, con una cultura industrial genuina y con estrategias de los grandes mundiales.

Los territorios de la reestructuración industrial en la RMBA son nuevos exponentes de espacialidades de cuencas de empleo y subempleo. En la medida en que se reduce el número de trabajadores, se reduce también el salario relativo, se incrementa el nivel de calificación al interior de las plantas y se terciariza el empleo con niveles de calificación heterogéneos. Se produce un proceso de selección donde los menos calificados y los menos polivalentes pierden. La reestructuración actual contribuye a relativizar factores de localización industrial tradicionales. Hoy no es más un obstáculo localizar una empresa en el extremo de una metrópolis de $160 \mathrm{~km}$ de longitud, lo que no significa que lo sea en términos de un deterioro en las condiciones de trabajo.

Las normas de calidad en procesos, propias de empresas reconvertidas, contribuyen notablemente a reducir los conflictos ambientales. Pero en la medida que los territorios de la reestructuración industrial en la RMBA son más sustentables en su dimensión ambiental, son también socialmente más "excluyentes" y económicamente más "inequitativos" que los anteriores territorios de la industrialización; ello se acentúa desde el momento que una gran parte de los empresarios no está en condiciones de incorporarse a la carrera de la competitividad.

La escala meso: Estos territorios de la reestructuración industrial, en la mayoría de los casos no tienen espacialidades definidas, sino lógicas de ocupación dominantes. Entre los senderos industriales de empresarios y la materialización en el territorio de establecimientos de todos los tamaños hay 13 millones de personas, más de 150.000 manzanas y otras nueve lógicas de ocupación territorial $^{16}$, además de la industrial. En síntesis, se trata de: 1, Centro

cida síntesis, hasta 1880, podemos mencionar la aldea de Buenos Aires, con una escasa producción artesanal, su incipiente puerto, los "caminos reales", las quintas de frutas y verduras, las barracas de esclavos, el Río de la Plata y el Riachuelo de los Navíos, como los principales componentes de la organización territorial durante casi dos siglos: saladeros, manufacturas casi artesanales, un significativo comercio portuario de ultramar y el origen de localidades periféricas que se incorporan al proceso algo mas tarde. Desde la gran inmigración europea el proceso deviene notablemente complejo: en medio siglo-1880/1935- la ciudad multiplica por cinco su población y por ocho su superficie. Entre 1947 y 1991 la RMBA pasa de 4,7 a 11,5 millones de habitantes, estimándose actualmente una superficie de $4.456 \mathrm{~km}^{2}$.

${ }^{15}$ En la definición de estas instancias han estado presentes largas discusiones y muchos momentos creativos compartidos con mi amigo Sergio Resa, y con otros amigos y compañeros, a quienes les agradezco esta posibilidad, no haciéndolos responsables de estos párrafos.

${ }^{16}$ Elegimos el concepto "lógica de osupación" en lugar de otros como los de "formas o modos de ocupación del suelo", porque ello supone una profundización en el conocimiento de los procesos que permiten explicar la naturaleza compleja de cada una de las manifestaciones territoriales, diferenciadas por sus rasgos 
metropolitano; 2, Subcentros metropolitanos, urbanos y locales; 3, Corredores; 4, Localidades y barrios consolidados; 5, Agrupamientos de zonas industriales; 6 , Grandes equipamientos; 7, Ámbitos residenciales no consolidados; 8, Ámbitos periurbanos residenciales y de esparcimiento; 9, Ámbitos periurbanos productivos y 10, Ámbitos naturales o con recursos degradados. Una política de ordenamiento territorial para la industria metropolitana no puede dejar de incorporar las lógicas de ocupación entre las que se despliega.

Hay "efectos de aglomeración industrial" con un "capital formal" -servicios de base, equipamientos- pero también hay mucho trabajo por hacer en términos de "capital organizacional", en particular la formación y la gestión de la empresa. Asímismo hay "deseconomías de aglomeración" por congestión, saturación, deterioro del medio e incompatibilidad entre lógicas de ocupación que Buenos Aires está consolidando en su centro y en algunos sectores de su primera corona. Emergen claramente "fortalezas territoriales genuinas" y "fortalezas intrafirma" desterritorializadas en la escala local; no obstante, sus rasgos distintivos no alcanzan a conformar territorios que respondan exclusivamente a una u otra "fortaleza".

La escala micro: Los territorios de la reestructuración industrial identificados en la RMBA constituyen aproximadamente 95 lugares $^{17}$. Concentran en una superficie aproximada del $1 \%$ de la región más de un tercio de lo que ella produce, un sexto de la población activa, la mitad del transporte automotor pesado de la región y una porción mucho menor de los conflictos ambientales que la industria provocaba hace una década.

Los rasgos característicos nos permiten definir estos territorios en términos de patrones territoriales de la industria en la RMBA. Se trata de territorios a escala barrial o local con caracteres industriales más o menos semejantes, definidos a partir de su trayectoria industrial y de doce rasgos considerados representativos del proceso de industrialización y de la actual reestructuración ${ }^{18}$.

A partir de la consideración de los rasgos semejantes, identificamos finalmente trece patrones territoriales de la industria. Los hay más ganadores, más perdedores, pero ninguno de ellos es campeón ni último. Veremos más adelante, en que medida cada uno de ellos se aproxima a los cuatro tipos territoriales que hemos analizado.

Proponemos veinticinco indicadores para evaluar los territorios de la reestructuración industrial ${ }^{19}$. La matriz que realizamos intenta sintetizar el

esenciales, mas que por su forma o su función.

${ }^{17}$ A partir del reconocimiento de las principales características de su trayectoria industrial, de la correlación espacial de 347 zonas y agrupamientos in dustriales tratados en el AIMBA -Atlas Industrial Metropolitano- y en la MiTs -Matríz Industrial Territorial Síntesis - y se du articulación con las nueve lógicas de ocupación restantes en la RMBA, se definen finalmente 95 territorios. Deseo expresar mi agradecimiento a Silvina Fernández para concluir este interminable trabajo.

${ }^{18}$ En resumen, se trata de: espacio industrial construído, establecimientos industriales, agrupamientos y zonas por rama industrial, gran industria, Pymes, micro-industrias; un sector representativo en reestructuración: complejo automotriz; compra y venta de inmuebles industriales; remates y subastas industriales por rama, por patrón territorial y por lugar; inversiones industriales recientes por municipio; inversiones en nuevas plantas; y empresas francesas radicadas en Argentina.

${ }^{19}$ Se trata de los siguientes indicadores: 1- trayectoria industrial, 2- trayectoria barrial, 3- trayectoria de centralidad, 4- trayectoria periurbana, 5-relación con lógicas de ocupación, 6- espacialidad fís ica natural, 7-con- 
comportamiento dominante de cada uno de ellos en los trece patrones territoriales identificados hasta la actualidad. La complejidad interna de cada patrón territorial - los trece totalizan casi un centenar de territorios de la reestructuracion industrialnos permite operacionalizar cualitativamente su tratamiento, seleccionando tres valores que representan la intensidad o el peso relativo de cada indicador.

Finalmente, se establece cuál de los cuatro territorios de la reestructuración se aproxima mejor a cada patrón territorial. En futuras propuestas, características de estos pesos relativos podrán interpretarse positiva o negativamente, proporcionándonos elementos que nos permitirán definir estrategias.

En este contexto, la definición de una política industrial viable para la industria en reestructuración debe partir del reconocimiento de los rasgos más dinámicos inherentes a cada patrón territorial, tanto los positivos como los negativos, así como los complejos matices que cada lugar pueda tener en todos o en cualquiera de los cuatro tipos territoriales reconocidos en la investigación: atractividad, pseudo-atractividad, cementerio industrial y tejido mixto.

\section{QUÉ POLÍTICA TERRITORIAL PARA LA INDUSTRIA METRO- POLITANA.}

En la Argentina hay una debilidad notoria e histórica en materia de políticas territoriales para la industria en los niveles institucionales, nacional, provincial y municipal. A pesar de la escasa importancia que tienen frecuentemente las espacialidades y una cierta concepción subyacente de territorialidad en la elaboración de una política industrial, una política territorial para la industria en reestructuración debe necesariamente articularse con el perfil dominante de la política industrial.

Esta política territorial debe orientarse a encontrar -o bien a generar- las espacialidades más ventajosas que en cada caso tienden a producir actualmente todos los territorios de la reestructuración, los ganadores y los perdedores, los atractivos o los pseudo-atractivos, los cementerios y los mixtos.

Suponiendo que, al menos, se suceden y/o coexisten tres criterios de política industrial (PERES NUNES, 1993) ${ }^{20}$ estimamos conveniente profundizar en acciones concretas, analizar el estado de puesta en marcha de programas asociados en el centenar de territorios estudiados, con sus espacialidades más salientes. Así aparecerán nuevos instrumentos que permitirán plantear una estrategia territorial industrial más genuina que la suma de Parques Industriales, SIP-Sectores Industriales Planificados y Zonas Industriales de

\footnotetext{
flictos ambientales reales y/o potenciales, 8- espacialidad física construída, 9-infraestructura y servicios, 10medio industrial local, 11- situación normativa, 12- ventajas fiscales, 13- tendencias de inversion industrial, 14tendencias de desindustrializacion, 15- reconversión industrial en procesos, 16- reconversión industrial organizacional, 17- dinámica de fusiones y adquisiciones, 18-cambio en el peso relativo de ramas y nichos, 19-eshbonamientos hacia atras, 20- eslabonamientos entre industrias, 21 - conectividad social en términos de cuencas de empleo y subempleo, 22- accesibilidad económica en términos de red vial de transporte de cargas, 23-centros científicos y tecnológicos, 24- posición en el mercado urbano, y 25- posición en el Mercosur.

${ }^{20}$ Al analizar la política industrial de los años noventa en América Latina, el autor (1993:43) reconoce tres criterios que permitirían establecer prioridades para su aplicación; se trata en síntesis de: 1- políticas de estímulos a mecanismos de mercado; 2 - políticas de tipo territorial neutra u horizontal; y 3- políticas de intervención directas a nivel sectorial.
} 
ordenanzas de usos. No olvidemos que al menos el $80 \%$ de la industria se encuentra fuera de áreas industriales planificadas reconocidas por la legislación provincial.

Es válido, según nuestra opinión, considerar la definición de una política territorial metropolitana para la industria desde el máximo nivel institucional, en este caso la Secretaría de Industria de la Nación. Para su concretización y su gestión es más viable acompañarla con la participación de los otros niveles de la administración: la Provincia y los Municipios; en este contexto institucional se sugiere incluir la competencia provincial, aún considerando que las reparticiones públicas encargadas de normar sobre Parques, SIP y Zonas Industriales son diferentes ${ }^{21}$.

Hace ya diez años que investigamos los territorios de la Región Metropolitana $^{22}$. En este marco, ¿qué política territorial de apoyo a la industria pensamos es favorable para no profundizar el cementerio industrial de la primera corona metropolitana?. Las microempresas tienen altas tasas de cierre y de recambio, las pequeñas Pymes vegetan, mueren... Pero muchas luchan y se esfuerzan por sobrevivir, mientras que otras de debaten para subir al tren de la competitividad. ¿De qué manera poder ofrecerles una mano en lo concerniente a la relación territorio-industria?.

En el mundo industrial metropolitano de Buenos Aires hay ámbitos en los cuales se observa una importante maduración en la gestión empresarial y pública local que tiende a apoyar la creación de medios industriales planificados, pero existen dificultades en la detección de los mejores lugares para la radicación industrial, considerando fundamentalmente las lógicas de ocupación, la conectividad y la accesibilidad. En la mayoría de los casos estamos en los núcleos del cementerio industrial y de los tejidos mixtos mencionados.

No obstante, la presencia de lugares en municipios con una importante trayectoria industrial o con elementos favorables que permitirían la posibilidad de llegar a promover la creación de agrupamientos industriales planificados, no hemos verificado en todos los municipios trayectorias de gestión del empresariado local ni de las instituciones locales que permitan confirmar la existencia de un medio actualmente favorable para la instalación.

Considerando inclusive ventajosas trayectorias industriales y elevadas tasas de accesibilidad y conectividad en relación a otros agrupamientos, como también compatibilidades entre lógicas de ocupación, debemos subrayar que si no hay

\footnotetext{
${ }^{21}$ En el informe recientemente presentado a la Secretaría de Industria de la Nación habíamos realizado más de 600 entrevistas en los 134 municipios de la provincia, así como en cuatro reparticiones provinciales: la Secretaría de Industria, la Secretaría de Política Ambiental, la Secretaría de Tierras, Urbanismo y Vivienda y la Subsecretaría de Asuntos Municipales. Ello orienta la investigación suponiendo la existencia de trayectorias institucionales sobre la industria, paralelas y no siempre articuladas; esto se presenta en lo relativo a los usos del suelo y al ordenamiento territorial. Esta situación se traduce en normas que regulan el territorio provincial con diferentes alcances: LEY 10.119 de Parques Industriales, LEY 11.459 de Radicación Industrial y DECRETOLEY 8912 de Ordenamiento Territorial y Uso del Suelo.

${ }^{22}$ Los territorios estudiados en la tesis permiten ofrecer aplicaciones en tres niveles institucionales: zonificación industrial para ordenanzas municipales de usos del suelo, contribuciones y ajustes a la legislación provincial reciente en el tema industrial y bases para una estrategia de ordenamiento territorial metropolitano en la industria por parte del Estado nacional. En este trabajo avanzamos hacia la definición de una política territorial para la industria metropolitana.
} 
madurez suficiente en la gestión, ni un interés orientado a la construcción de un mínimo espacio de consenso, los Parques o SIP corren el riesgo de naufragar totalmente, derivando en una pseudo-atractividad territorial que finalmente hace fracasar al agrupamiento industrial. Este argumento tiene un fuerte peso a la hora en que se define una estrategia de inversión industrial de apoyo a la creación de Parques y SIP.

En 1999, aún subsisten grandes diferencias entre la distribución de los agrupamientos oficiales planificados y la repartición real de las industrias. Hay también diferencias entre aquello que está normado, lo real investigado y los lugares con mayor atractividad territorial.

En la primera corona metropolitana se encuentran los lugares potencialmente más conflictivos de la RMBA. Considerando la diferencia que supone en la lógica de ocupación, un tejido microempresarial en relación a un tejido Pyme -en medios con importante trayectoria barrial- proponemos la complementariedad de tres estrategias mixtas público-privadas en relación a la localización industrial ${ }^{23}$. En ellas subyacen políticas territoriales explícitas de apoyo a la localización industrial. Podemos resumirlas de la manera siguiente:

1. El apoyo al conjunto del microempresariado y del empresariado Pyme de Nivel de Complejidad Ambiental 1, que no acarrea conflictos con el barrio donde se instala, esencialmente en lo relativo a la oferta de espacio para la expansión de sus procesos productivos.

2 La posibilidad de profundizar la experiencia -aunque pequeña con éxito- de los casos aislados de incubadoras de microempresas y de pequeñas Pymes, fundamentalmente para los casos de empresarios con dificultades por falta de espacio para la realización de procesos productivos en su propiedad.

3 La posibilidad de concretar la realización de Parques Industriales Pyme pequeños y medianos- en una decena de municipios de la primera corona metropolitana: aquellos con mayor trayectoria industrial. Proponemos aquí los ámbitos en condiciones de aprovechar las ventajas comparativas que suponen la proximidad a cuencas de empleo y subempleo con niveles de calificación medios y altos existentes; pero también reconocer las ventajas que supone la maduración de políticas y de acuerdos locales, principalmente en municipios que buscan alternativas para no profundizar la "sangría industrial" de las últimas dos décadas.

En la segunda y tercera corona metropolitana los riesgos y las amenazas son diferentes. En estos últimos años se observa un fuerte impulso dirigido a emprender actividades industriales, comerciales mayoristas y de distribución. En este contexto consideramos que los territorios posibles no son solamente aquellos normados por la provincia, es decir Parques, Sectores y Zonas Industriales, sino también playones de quiebre de cargas, centros de servicios al transporte y a la industria, parques temáticos, parques polivalentes y ciertas plataformas logísticas. Sin embargo, no parece aún posible en Buenos Aires implantar los parques ni los

\footnotetext{
${ }^{23}$ En estas tres estrategias consideramos adecuado trabajar a nivel inter-institucional para aproximar aún más algunas regulaciones específicas vigentes: hacemos alusión a las Leyes provinciales de Ordenamiento Territorial 8912/77 y de Radicación Industrial 11459/95, así como a sus Decretos Reglamentarios, pero también a la nueva Ley provincial Pyme y a Ordenanzas y Decretos municipales que reglamentan la instalación de pequeñas empresas.
} 
polos tecnológicos, y más aún, tampoco encontramos el germen para tecnópolis, al menos con un carácter de atractividad territorial genuino.

Actualmente los territorios con mayor atractividad territorial no responden a iniciativas públicas sino privadas. Encontramos casos de generación de una combinación fortuita de inversones privadas en corredores rápidos de la segunda corona metropolitana realizados originalmente por el Estado; también identificamos el importante sendero industrial de algunos empresarios ${ }^{24}$.

Pero "no todo lo que brilla es oro". Crear un parque industrial o una plataforma logística es una cosa, pero tener éxito es algo muy diferente. No alcanza con disponer de terrenos en cantidad suficiente, tampoco con parcelas con servicios a bajo costo, o incluso gratuitas. Los empresarios evalúan otros aspectos cuando eligen un sitio para instalar su empresa. Y parecería que en numerosas oficinas de planificación municipal, no únicamente de la RMBA, sino de todo el país, los profesionales y los técnicos no conocen más que una parte de la realidad.

¿Qué queda entonces para los empresarios que hoy intentan hacer en dos o tres años lo que a otros les llevó veinte o treinta años?. ¿Cuál es el lugar de la cultura industrial y cuál el de la lógica de la inversión en los sectores más rentables?. Hoy, empresarios grandes y medio-grandes, definen en sus estrategias de inversión inmobiliaria, lo industrial como nicho entre aquellos más dinámicos: torres de departamentos de lujo, viviendas en copropiedad, edificios inteligentes, clubes de campo, barrios cerrados, grandes centros comerciales, autopistas con peaje... . Las fortalezas no se obtienen solamente por la concreción de oportunidades, hay una base más sólida que motiva el éxito. En lo relativo a la reestructuración industrial, encontramos aquí, la trayectoria industrial, la aceptación del cambio que suponen las nuevas formas de producción y de organización en la planta, las negociaciones organizadas, la creación de entornos locales favorables, los acuerdos graduales en término de modus operandi, la generación de espacios comunes de concertación entre el Estado y los grupos empresarios... . Todos constituyen los nuevos escenarios para los eventuales territorios de la reestructuración con atractividad genuina.

Una de las formas de operacionalizar esta concepción para una política territorial, inserta en el tejido institucional y normativo vigente, es evaluar las condiciones de atractividad territorial en cada uno de los agrupamientos industriales. Para ello proponemos identificar las fortalezas y debilidades de lugares a partir de la instalación, el desarrollo y la consolidación de industrias y de empresas asociadas a los circuitos mencionados ${ }^{25}$. La intención final es identificar cuáles podrían ser las líneas de inversión a potenciar en cada agrupamiento en función de los grados de desarrollo, de maduración y de trayectoria registrados.

\footnotetext{
${ }^{24}$ Entre los 95 territorios, identificamos dos corredores principales, el más importante hacia el norte y el otro hacia el sur; se trata respectivamente de la primera autopista metropolitana -la Panamericana- entre el Arroyo Basualdo y la ciudad de Garín, y la Autopista-Ruta 2 entre el Arroyo Conchitas y la localidad de El Pato. En lo relativo a los empresarios cabe destacar el caso de Meyer Oks, el gestor de los Parques Industriales Oks en 1959 y Pilar en 1972.

${ }^{25}$ Para evaluar la atractividad territorial trabajamos al menos con diez aspectos; en síntesis se trata de: 1-perfil industrial; 2- disponibilidad de suelo; 3- nivel de inversión; 4- beneficios fiscales; 5- gestión; 6-infraestructura; 7-accesibilidad; 8- entorno empresarial; 9- lógicas de ocupación y 10-relación con el medio físico.
} 
Los criterios de priorización de la inversión de apoyo a la creación, consolidación y/o fortalecimiento de agrupamientos industriales comienzan a surgir de la combinación de al menos cuatro aspectos: la trayectoria industrial, las lógicas de ocupación, la accesibilidad y conectividad, y el escenario favorable para la maduración de estos aspectos.

No creemos conveniente "barajar y dar de nuevo", tampoco creemos en la improcedencia de lo actualmente regulado en materia de agrupamientos industriales a nivel provincial. Proponemos una segunda vuelta en el sendero de apoyo a la creación de Parques y SIP, allí donde las instituciones competentes al menos hace dos décadas lo realizan. Es conveniente profundizar la investigación para detectar las posibles líneas de apoyo a políticas territoriales para la industria en aquellos lugares que tienen mejores condiciones para la radicación industrial en relación a muchos otros hoy existentes en las normas provinciales y municipales.

Hace más de dos décadas se afirmaba, “...ya no es más la industria quien crea la ciudad, sino la ciudad la que desarrolla la industria" (CASTELLS, 1975). Hoy la reestructuración industrial no crea la ciudad, y ésta tampoco desarrolla la industria: la reestructuración económica mundial "co-construye" las metrópolis de paises periféricos, que se van transformando en el escenario predilecto de una competencia mas salvaje que en las metrópolis de países innovadores.

La industria de una metrópolis de un país no central del mundo globalizado debe ya definir una política territorial que incluya necesariamente las fortalezas y las debilidades de la reestructuración industrial. De esta manera podrá amortiguar el impacto ocasionado por el croupier cuando pone una ficha en Buenos Aires entre muchas- sobre un tablero de juego mundial, consolidando las decisiones de gigantes económicos, en una estrategia dominante alejada del anclaje en cada territorio, y más próxima a la internacionalización de sus mercados, marginando a medio camino a políticos y decisores... . Tratamos de responder en particular a ganadores y perdedores, a atractividades auténticas y a cementerios industriales en la metrópolis con la más larga historia industrial de América Latina.

\section{BIBLIOGRAFÍA.}

- AZPIAZU; D. y NochtefF, H. (1994): El desarrollo ausente. Buenos Aires, Flacso-Tesis Norma.

- BORON, A. (1989): «Los actores y el libreto: Los sujetos sociales de la reconversion industrial en Argentina», en Industria, Estado y Sociedad. La reestructuración industrial en América Latina y Europa.(pp.365-391), Caracas, Eural. Nueva Sociedad.

- BOZZANO, H. (1997): «Qué Industria para qué Ciudad. La aplicación de las leyes N 8912/77 y 11459/95 en la Región Metropolitana de Buenos Aires», en Revista Argentina del Régimen de la Administración Pública. Suplemento Especial N 2 Année XIX. 1997.

- Bozzano, H. (1999): «Les Territoires de la Restructuration Industrielle dans la Région Métropolitaine de Buenos Aires». Thèse de Doctorat sous la direction de Jean Revel-Mouroz. IHEAL. Université de París III - Sorbonne Nouvelle. (576 p. et 226 cartes) 
- BozzANo, H, NACLeRIO, A., FERNÁNDEZ, S. et AL (1999): «Parques, Sectores y Zonas Industriales de la Provincia de Buenos Aires. Conformación de una base de datos y Evaluación de la localización existente». Informe CEB Centro de Estudios Bonaerense. Proyecto PNUD Arg 98/013. Secretaría de Industria, Comercio y Minería, Ministerio de Economía de la Nación, Buenos Aires

- CHIOZZA., E. (1983): «La integración del Gran Buenos Aires», en Buenos Aires Historia de Cuatro Siglos (pp.421-449), Buenos Aires, Ed.Abril.

- CORAGGIO,J. L. (1989): «Sobre la espacialidad social y el concepto de región», en Territorios en Transición, Quito, Ed. Ciudad.

- CUADRAdo Roura, J. R. (1989): «Facteurs de localisation industrielle. Nouvelles tendances», en Revue d'Economie Régionale et Urbaine. N⒊ Paris, pp.471-490).

- GUIMARAES, R. (1998): Aterrizando una Cometa: Indicadores de sustentabilidad, DPPR. Río de Janeiro.

- JAVET, H. (1993): «Territoires et concurrence territoriale», en Revue d'Economie Regionale et Urbaine. $\mathrm{N}^{\mathrm{o}} 1$, París.

- KATZ, J. (1996): «Las estrategias de las empresas: Resultados de un conjunto de estudios latinoamericanos», en Seminaire Reconversión Industrial e Integración Latinoamericana. Proyecto Multinacional Materiales OEA-CNEA. Centro Atómico Constituyentes, Buenos Aires.

- KOSACOFF, B. y BEZCHINSKY, G. (1993): «De la sustitución de importaciones a la globalización. Las empresas trasnacionales en la industria Argentina», en KOSACOFF ET AL: El desafio de la competitividad. La industria Argentina en transformación. CEPAL/, Buenos Aires, Alianza Editorial.

- MaIllat, D., CReVOISIER, O. et LeCOQ, B. (1991): «Réseaux d'innovation et dynamique territoriale. Un essai de typologie», en Revue d'Economie Régionale et Urbaine. $\mathrm{N}^{\circ} 3 / 4$. Poitiers, pp.407-432.

- PERES Nunez, W. (1993): «¿Dónde estamos en política industrial?», en Revista de la Cepal, N 51, Buenos Aires.

- PERRIN, J.-C. (1990): «Organisation industrielle : La composante territoriale», en Revue d'Economie Industrielle . N51. Parí, pp.276-303.

- RAFFESTIN, C. et TURCO, A. (1984): «Espace et pouvoir», en Les concepts de la Géographie Humaine, París, Masson.

- ReVEL-MourOZ, J. (1992): «Territoires des nouvelles technologies», en Inovations technologiques et mutations industrielles en Amérique Latine. , $\mathrm{Pa}$ rís, IHEAL, pp.341-344.

- SCHVARZER, J. (1983): «La implantación industrial», en Buenos Aires Historia de Cuatro Siglos, Buenos Aires, Abril, , pp.223-239.

- SChVARZER, J. (1995): «Grandes grupos Económicos en La Argentina. Formas de propiedad y Lógica de Expansión», en KOSACOFF, B y SCHVARZER . Más allá de la estabilidad. Argentina en la época de la globalización y la Regionalización, Buenos Aires, Fundación Ebert.

- TADDEI, D. et CORIAT, B. (1993): Made in France. L'industrie française dans la compétition mondiale. París, Le Livre de Poche-Librairie Générale Française, $471 \mathrm{pp}$. 